\title{
PELATIHAN LANSIA BEBAS NYERI LUTUT DI PATUKAN AMBARKETAWANG KECAMATAN GAMPING KABUPATEN SLEMAN
}

\author{
Yoni Astuti $^{1 *}$, Triwulandari Kesetyaningsih ${ }^{2}$, Ambar Relawati $^{3}$ \\ ${ }^{1}$ Fakultas Kedokteran dan Ilmu Kesehatan, Universitas Muhammadiyah Yogyakarta dan \\ Pusat Studi Wanita, Universitas Muhammadiyah Yogyakarta, Indonesia \\ ${ }^{2}$ Fakultas Kedokteran dan Ilmu Kesehatan, Universitas Muhammdiyah Yogyakarta, Indonesia \\ ${ }^{3}$ Magister Keperawatan, Universitas Muhammadiyah Yogyakarta, Indonesia \\ *Corresponding author: yonia@,umy.ac.id
}

Received 1 January 2020; Accepted 28 February 2020; Available online 29 February 2020

\begin{abstract}
Abstrak
Meningkatnya usia harapan hidup masyarakat Indonesia perlu diimbangi dengan kemampuan kemandirian pada aspek kesehatan bagi komunitas lansia. Dusun Patukan Ambarketawang Yogyakarta termasuk tinggi angka lansianya. Keluhan nyeri lutut banyak dialami oleh lansia yang berdampak pada berkurangnya aktifitas dan produktifitas mereka. Senam isoquadrisep salah satu upaya nonfarmakologik yang dianjurkan untuk mencegah nyeri lutut. Posyandu Lansia dusun Patukan Ambarketawang Gamping Sleman melaksanaan aktifitas rutin mengontrol kesehatan dengan memeriksa tekanan darah. Kader posyandu dan peserta lansia belum mengenal senam isoquadrisep pada bagian lutut untuk mengurangi nyeri lutut pada lansia. Pengabdian kemitraan Masyarakat dilakukan membentiuk Kader dan pelatihan senam isoquadrisep untuk mencegah lansia dengan nyeri lutut. Metode untuk kegiatan ini adalah TOT senam quadricep untuk kader dan beberapa masyarakat. Hasil kegiatan ini adalah kader memasukkan senan lutut untuk dilakukan saat posyandu lansia bergantian dengan senam yang sudah ada sebelumnya di Dusun Patukan.
\end{abstract}

Kata Kunci : Senam isoquadricep, nyeri lutut, lansia

\section{Abstract}

The increasing of Indonesian life expectancy needs to be balanced with the ability of independence in the health aspect of the elderly community. Patukan Ambarketawang Yogyakarta has high in a number of elderly people. Knee pain experienced by the elderly, which have an impact on reducing their activity and productivity. Isoquadrisep exercises are one of the non-pharmacological efforts that are recommended to prevent knee pain. Elderly Posyandu in Patukan Ambarketawang Gamping Sleman village conducts routine activities to control the health of the elderly in general such as to measure blood pressure. Posyandu cadres and elderly participants are not familiar with isoquadrisep exercises on the knee to reduce knee pain in the elderly. Community partnership service is carried out to form cadres and isoquadrisep exercise training to prevent elderly with knee pain. The method for this activity is Training Of Trainer on quadriceps exercise for cadres and some communities. The results of this activity are cadres have an isoquadricep exercise agenda at each elderly meeting alternating with other exercises that already existed in Patukan Ambarketawang Gamping.

Keywords: Isoquadricep exercise, knee pain, elderly 


\section{PENDAHULUAN}

Kabupaten Sleman memiliki rerata Umur Harapan Hidup (UHH) penduduk tertinggi di Indonesia. Adapun jumlah penduduk pra usia lanjut (45-59 tahun) sejumlah 53.146 jiwa dan penduduk lansia ( $>60$ tahun) ada 55.967 jiwa, dari total penduduk 1.090.567 jiwa. Jumlah penduduk lansia yang banyak perlu perhatian serius di bidang kesehatan agar tidak menjadi beban sehingga perlu program promotif preventif.

Salah satu gangguan kesehatan yang umum terjadi pada lansia adalah nyeri lutut. Nyeri yang ditimbulkan biasanya akibat osteoarthritis. Di Indonesia osteoarhritis ditemukan pada $15,5 \%$ pria dan $12,7 \%$ wanita denga $n$ prevalensi secara umum mencapai $5 \%$ pada usia < 40 tahun, $30 \%$ pada usia 40 - 50 tahun, dan $65 \%$ pada usia $>61$ tahun. Dengan meningkatnya jumlah lansia dipediksikan akan meningkat juga penderita osteoarhtritis sehingga pasien lansia dengan keluhan nyeri lutut pun akan meningkat.Nyeri lutut mengakibatkan gangguan aktifitas juga menimbulkan kecemasan pada lansia.

Berdasarkan wawancara dengan beberapa kader posyandu lansia (ibu Erna dan Ibu Ukin) bahwa dusun Patukan memiliki kegiatan posyandu lansia yang rutin melakukan pertemuan bulanan setiap tanggal 3. Peserta lansia berjumlah sekitar 60 orang dengan usia 57-77 tahun.

Kegiatan rutin yang dilakukan adalah pengukuran berat dan tinggi badan, pengukuran tekanan darah, jika ada waktu dilakukan senam jari tangan, serta pemantauan kesehatan dengan beberapa pertanyaan apakah merokok, apakah mengkonsumsi serat, apakah beraktifitas fisik, apakah menderita DM (diabetes Mellitus).

Namun pada prakteknya tidak semua kader melakukan pertanyaan tersebut. Disamping itu jika ada pertanyaan dari kader peserta lansia sering menjawab lupa ("Mbuh"/ndak tahu). Lansia hanya menggunakan lembar KMS (kartu menuju sehat) usia lanjut, namun sering tidak membawa saat pemerikasaan. Karena hanya satu lembar tipis dan sering hilang/ lupa saat menyimpan.

Berdasarkan wawancara denga ibu Ukin ternyata banyak peserta lansia mengeluhkan nyeri lutut, terutama pada lansia perempuan. Rasa nyeri yang diakibatkannya membuat para lansia bermasalah dalam melakukan aktivitas sehari - hari seperti berpindah posisi dari duduk atau berbaring, berjalan, menaiki tangga, berdiri yang terlalu lama, sholat, dan pada keadaan lebih parah menyebabkan disabilitas sehingga memerlukan alat bantu untuk berjalan. Jika terdapat serangan nyeri, mereka berobat ke puskesmas dan diberi obat steroid.

Selama ini penggunaan obat asetaminofen dan non-steroidal anti inflammatory drugs (NSAID) untuk mengurangi nyeri dan anti inflamasi merupakan obat pilihan yang diresepkan oleh dokter. Obat - obat bebas penghilang rasa nyeri dan kekakuan sendi lutut juga banyak ditawarkan melalui berbagai media kepada masyarakat sejalan dengan semakin banyaknya keluhan nyeri sendi lutut dan kekakuan lutut di masyarakat. Center for Disease Control (2011) memberikan pernyataan bahwa penggunaan jangka lama obat-obatan tersebut kurang dianjurkan karena akan menimbulkan efek samping. Salah satu cara untuk mengurangi nyeri yaitu dengan latihan (Exercise). Pelatihan yang dianjurkan adalah dengan latihan isokinetik. Latihan isokinetic merurupakan latihan dinamik yang dilakukan dengan kecepatan angular sendi yang konstan, yaitu otot berkontraksi memendek dan memanjang dengan laju yang konstan. Latihan ini telah terbukti mampu menurunkan nyeri sendi dan melenturkan otot sendi penderita osteoarthritis (Hayati A, 2014).

Tujuan Pengabdian Masyarakat ini untuk membantu mengatasi masalah yang terjadi di Patukan Ambarketawang gamping Sleman yaitu 1). Untuk meningkatkan pengetahuan kader lansia melati Patukan tentang pentingnya kemandirian lansia dengan tetpa sehat, 2) untuk meningkatkan keterampilan kader lansia dan masyarakat lansia tentang kemampuan melakukan latihan isoquadricept pada bagian kaki. 


\section{METODE PELAKSANAAN}

Untuk mewujudkan tujuan kegiatan ini maka dilakukan tahapan-tahapan metode dalam pelaksanaannya. Tahapan metode yang diterapkan yaitu penyuluhan (Ceramah dan diskusi), Penyuluhan berupa ceramah dan diskusi dilakukan untuk memberikan wacana tentang pentingnya kesehatan lansia yang terjaga untuk kemandirian lansia. Juga untuk memberikan wacana bagaimana melakukan senam isoquadricep untuk mencegah nyeri pada lutut. Pelaksanaan kegiatan di lakukan di Posyandu Lansia Dusun Patukan Ambarketawang Gamping Sleman. Peserta lansia Sejumlah 64 orang dengan jumlah kader Lansia sebanyak 16 orang.

\section{HASIL DAN PEMBAHASAN}

A. Pembekalan kesehatan lansia pada peserta posyandu lansia

Pembekalan kesehan lansia yang ditujukan pada peserta lansia Melati Patukan Ambarketawang dilakukan pada tanggal 3 Maret. Disamping itu pada kesempatan ini juga dilakukan pemerikasaan kesehatn lansia berupa, pemeriksaan tekanan darah, pengukuran berat badan dan tinggi badan serta lingkar perut, interview tentang asupan serat, pemeriksakaan kadar gula darah gratis. Jika diketahui kadar gula darah tinggi dan tekanan darah tinggi maka peserta diberi catatan ke keluarga untuk periksa ke puskesmas terdekat.
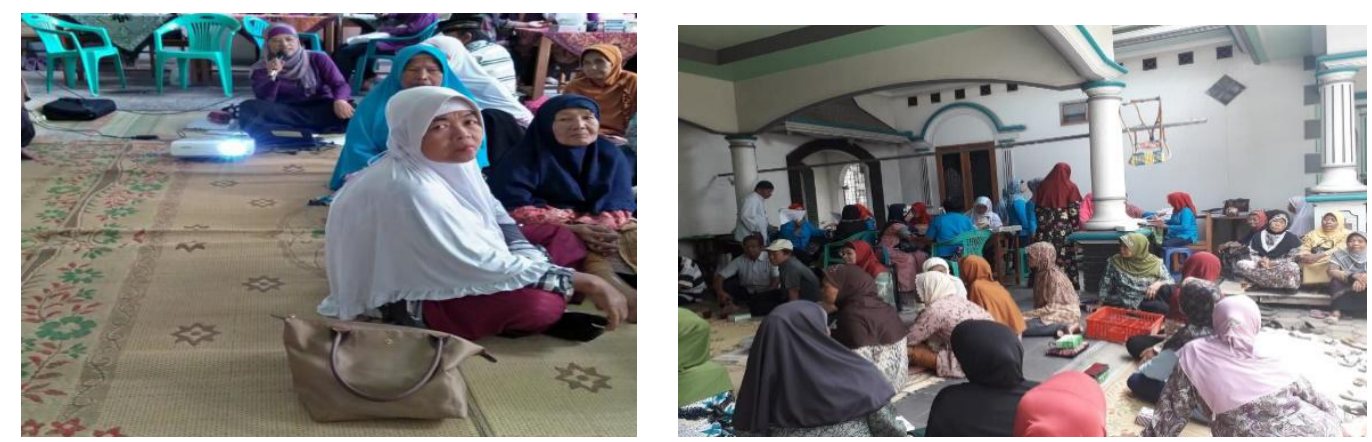

Gambar 1. Pembekalan materi kesehatan lansia di yandu lansia Melati

Pada ceramah ini juga dilakukan Tanya jawab seputar kesehatan lansia. Beberapa pertanyaan yang disampaikan peserta di bagikan dengan bertukar pengalaman ke sesama lansia sehingga kegiatan ini secara aktif melibatkan peserta dengan suka cita berbagi pengalaman . Hal ini dilakukan agar lansia tidak bosan dan kegiatan ini menjadi menarik bagi mereka. Pengalaman yang disampaikan peserta lain di bahas sesuai dengan dasar - dasar ilmu kesehatan lansia. Adapun kesehatan lansia yang harus dijaga antara lain kecukupan air, karena lansia sangat rentan mengalami dehidrasi, sehingga harus sering minum bukan banyak minum, di jauhi paparan yang memudahkan kehilangan air. Perlu kegiatan olah raga seperi jalan kaki, senam lansia, namun tidak diperkenankan terlalu berat, tidak diperkenankan mengambil barang- barang yang berat, menghindari kegiatan atau aktifitas yang dapat menyebabkan risiko jatuh. Kondisi tubuh diupayakann ideal, dijauhi obesitas central (bagian perut lebih besar), untuk lansia laki- laki, diupayakan berhenti merokok. Beberapa peserta adalah petani dan terbiasa dengan aktifitas sehingga selalu mencari kegiatan, sepert bersihbersih kebun, merapikan kayu dll, yang berisiko terluka. Hal seperti ini diingatkan untuk dikurangi, mengingat usia makin bertambah jika terluka lama sembuhnya. Lansia harus sering beristirahat dan kegiatan banyak dilakukan dengan duduk. Terlebih - lebih yang memiliki riwayat hipertensi dan gula. Hal yang penting ditekankan pada lansia Patukan adalah untuk tidak malu jujur bahwa tubuhnya sedang sakit, karena biasanya mereka tidak mau periksa jika ada rasa kurang enak badan. Alasan takut, dan keluarganya kurang peduli. 


\section{B. Pelatihan senam cegah nyeri lutut}

Pelatihan senam untuk mencegah nyeri lutut diberikan dengan percontohan. Hal ini bertujuan untuk memudahkan peserta melakukan senam sebagaimana mestinya agar bereffek pada menguatnya otot - otot sendi lutut sehingga menjadi lentur dan mampu menopang tubuh tanpa ada cidera. Kegiatan ini dilakukan di bulan april yang diikuti oleh 80 peserta lansia. Peserta berlatih melakukan senam yang sederhana ini namun membutuhkan pengulanagn yang adekuat atau sesuai untuk mampu menghilangkan nyeri dan kekakuan otot. Senam ini dapat dilakukan di mana saja. Saat di rumah dapat dilakukan sambil istirahat, kedua kakai di julurkan ke depan, betis dan paha menyentuh lantai kemudian otot paha ditarik, ditegangkan sehingga tempurung lutut tertarik ke belakang, ko ndisi ini ditahan dengan hitungan 8 kali, selelah itu tarikan dilepaskan, rileks dengan hitungan 6 kali, selanjutnya di ulangi lagi memarik otot bagian paha dengan kondidi seperti awal, hitungan 8 kali kemudian rileks lagi hitungan 6 kali. Hal ini diulang - ulang selama 8 kali. Setiap hari dapat dilakukan 3-4 kali. Sedangkan dalam seminggu dapat dilakukan 3-4 kali.

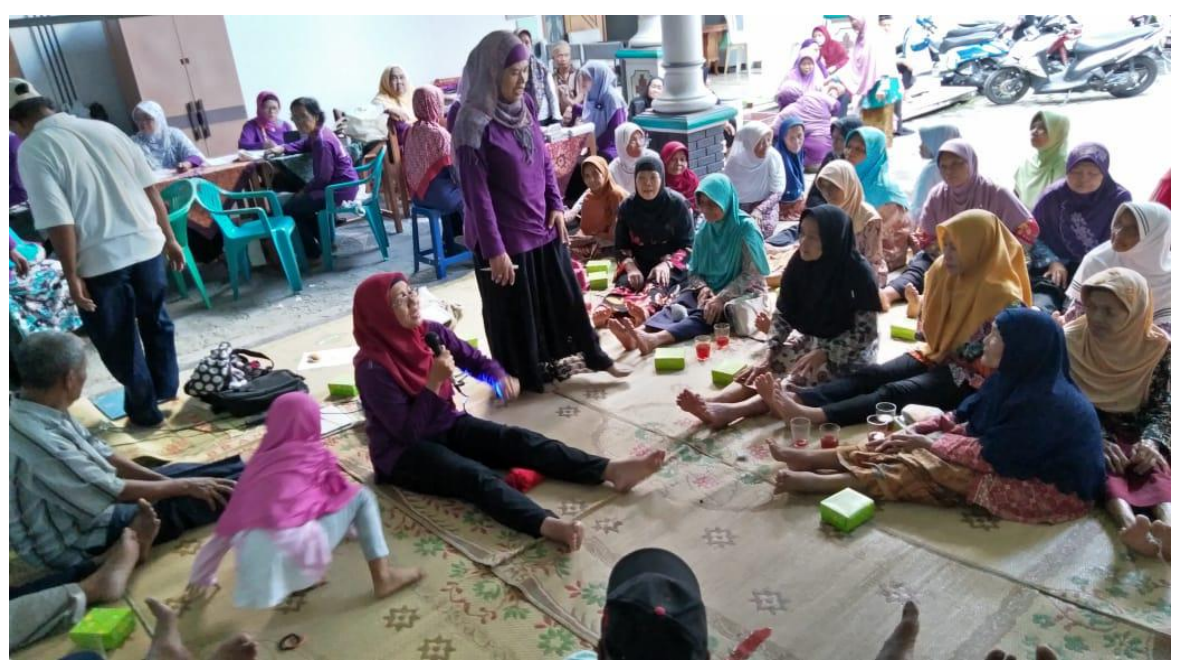

Gambar 2. Pelatihan senam isoquadricep untuk mencegah nyeri lutut

Selain peserta lansia kader juga ikut pada pelatihan ini, selanjutnya akan membentuk kader yang akan memberikan senam ini setiap ada pertemuan lansia. Agar nyeri lutut pada lansia dihindari sehingga mereka dapat beraktifitas normal.

\section{KESIMPULAN}

Kegiatan pengabdian masyarakat bebasis lansia dan kader di Patukan pada ranah pencegahan nyeri lutut penting di lakukan mengingat makin bertambahnya jumlah lansia dan pentingnya kemandirian mereka. Kemandirian diupayakan dengan terjaga kesehatan salah satunya dengan cukup aktifitas dan dihindarkan dari serangan nyeri lutut kemungkinan agar menjadi lansia bahagia dan produktif.

\section{UCAPAN TERIMA KASIH}

Ucapan terimakasih disampaikan kepada:

1. LP3M UMY atas program hibah pengabdian Ipteks bagi masyarakat.

2. RW 12 Tambakbayan Ngampilan atas kemitraan program pengabdian pada Masyarakat

3. PSW UMY atas program pemberdayaan perempuan di Kawasan Patukan Ambarketawang Gamping Sleman 


\section{DAFTAR PUSTAKA}

Schumacher, H.R., Eymont, M.J., Gordon, Hansel, J.R. 2008. The effect of synovial permeability and synovial fluid leukocyte counts in symptimat osteoarthritis after intraarticular corticosteroid administration. Journal Rheumatol, 9.

Shahnawaz, Anwar, MPT, Ahmad Alghadir M.S. 2014. Effect of Isometric Quadriceps Exercise on Muscle Strength, Pain, an Function in Patients with osteoarthritis : A Randomized Control Study. Journal of Physical Therapy Science.

Suriani, S., Lesmana, S.I. 2013.. Latihan Theraband lebih baik menurunkan nyeri dari pada latihan Quadriceps bench pada osteoarthritis genu. 13 (1).

Theresia, T. M. 2015. Efektifitas Latihan lutut terhadap penurunan intensitas nyeri pasien osteoarthritis lutut di Yogyakarta. Jurnal Keperawatan Sriwijaya, 2. ISSN No. 2355 245 . 